paraissent comme collés, car je n'ai pu les séparer qu'en exerçant sur eux une assez forte pression au moyen d'une petite spatule. M. de Boissy a opéré à son tour une nouvelle descente dans mon puits et a réussi à s'emparer encore de כ̆ sujets de la curieuse bête, sans compter les cadavres. "

Je suis certain que nos collègues seront frappés comme moi par ces cadavres abondants que l'on prend en compagnie de quelques sujets vivants; nous voyons aussi qu'un individu, conservé dans cette mème eau, est mort 10 heures après sa capture. Ces faits, absolument contraires à ce que l'on observe chez les Hydropores et genres voisins, indiquent évidemment que les Siettitia surprises dans le puits de M. Si etti y sont amenées de plus loin et n'y retrouvent plus le milieu qui leur est nécessaire : ce puits, je le répète, étant alimenté par une source hypogée dont on ignore l'origine exacte, nos premières suppositions, a savoir que notre insecte a son centre d'origine dans une masse liquide éloignée, se trouvent pleinementjustifiées. Reste à découvrir cette nappe ou ce cours d'eau souterrain; devant la réussite des recherches de nos amis, il ne faut plus désespérer de rien.

\title{
Description d'un Cérambycide nouveau appartenant au genre Corem1a et tableau synoptique de ce genre [COL.]
}

par E. Gounelle.

Goremia Bruchi, spec. nov. - Linearis, scabra, supra subtilissime subtus densius argenteo sericea, plumbeo-nigra, antennis ferrugineo-piceis, scapo nigro, pedibus rufis tibiarum femorumque posticorum apice nigra excepta; caput antice in rostrum paulo productum; antennae tenues, apicem versus haud incrassatae, ơ corpore fere duplo longiores, o elytrorum apicem vix superantes, scapo brevi, crasso, subtus incurvato, supra basi excavato, art. $3^{\circ}$ sequente duplo longiore, $5^{\circ}$ praecedente longiore; thorax elongatus, antice angustior, lateraliter ante medium tumidus; scutellum parvum, apice rotundatum, dense argenteo-sericeum; elytra latitudine triplo longiora, depressa, parallela, apice conjunctim ovata; pedes antici breves, postici valde elongati, femoribus posticis basi gracilibus apiceque abrupte et valde clavatis; tibiis posticis apice incurvatis et crista pilorum nigrorum ornatis; tarsi postici valde elongati, art. $1^{\circ}$ ceteris simul sumptis vix breviore, art. $3^{\circ}$ minutissimo. - Long. : 8,3-10 mill. Lat. : 1,6-2 mill. 
République Argentine, prov. de Tucuman (G. Baer); prov. de Catamarca (C. Bruch); nombreux exemplaires.

$C$. Bruchi a la forme grèle de $C$. hirtipes Oliv. et signaticollis $\mathrm{Bu}-$ quet, qui constituent le genre Coremia proprement dit, et la tête un peu allongée en museau de la première de cesespèces; d'autre part elle se rapproche de $C$. erythromera dont Serville avait fait une section que Thomso n a plus tard érigée en genre, par la couleur de ses pattes, par la longueur moins grande de ses fémurs postérieurs et surtout par la forte massue qui termine brusquement ces mêmes fémurs. C'est done là une forme intermédiaire réunissant les caractères les plus importants du genre principal et quelques-uns de ceux, de valeur assez discutable d'ailleurs, sur lesquels Thomson s'était fondé pour établir son genre Thalusia. Ce dernier n'a plus, par conséquent, sa raison d'ètre et doit être placé en synonymie.

\section{Tableau des espèces.}

1. Antennes grossissant très légèrement et progressivement à leur extrémité; fémurs postérieurs ayant la mème longueur que le corps et terminés par une massue fusiforme; pattes de la mème couleur que le corps; tarses

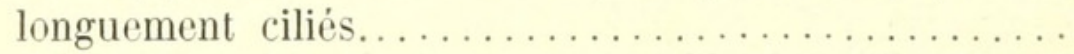

$1^{*}$ Antennes non épaissies à leur sommet; fémurs postérieurs de la longueur des élytres seulement et terminés brusquement par une forte massue; couleur des pattes différente de celle du corps; tarses non ciliés............

2. Joues assez allongées; élytres échancrés au sommet, les angles de l'échancrure dentiformes........... hirtipes.

$2^{*}$ Joues plus courtes; élytres subarrondis oú ovalaires à leur

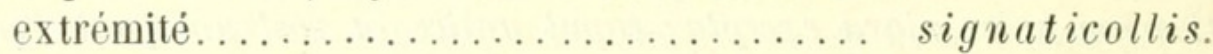

3. Corps linéaire; joues assez allongées; antennes des ơ deux fois plus longues que le corps; scape et extrémité des tibias postérieurs de couleur noire............. Bruchi.

$3^{*}$ Corps plus robuste et plus court; antennes des ơ à peine plus longues que le corps; scape et extrémité des tibias de couleur rousse.................. ery thromera.

Distribution géographique. - Guyanes, Amazonie, Brésil central, oriental et méridional, Uruguay, région Nord-Ouest de la République Argentine. 


\section{$2 \mathrm{BHL}$ Biodiversity Heritage Library}

Gounelle, Pierre-Émile. 1905. "Description d'un Cérambycide nouveau appartenant au genre Coremia et tableau synoptique de ce genre [Col.]." Bulletin de la Société entomologique de France 1905, 227-228. https://doi.org/10.5962/bhl.part.26097.

View This Item Online: https://www.biodiversitylibrary.org/item/34157

DOI: https://doi.org/10.5962/bhl.part.26097

Permalink: https://www.biodiversitylibrary.org/partpdf/26097

\section{Holding Institution}

Smithsonian Libraries

\section{Sponsored by}

Smithsonian

\section{Copyright \& Reuse}

Copyright Status: NOT_IN_COPYRIGHT

This document was created from content at the Biodiversity Heritage Library, the world's largest open access digital library for biodiversity literature and archives. Visit BHL at https://www.biodiversitylibrary.org. 